\title{
PERSONAL KNOWLEDGE MANAGEMENT SYSTEM: ACCESSIBILITY, SHARING AND THE CORRECT SYSTEM ADDS VALUE TO KNOWLEDGE
}

\author{
Cynthia J. Gormley, Robert Morris University, cjgst16@mail.rmu.edu \\ Samantha J. Gormley, Robert Morris University, sjgst19@mail.rmu.edu
}

\begin{abstract}
Personal Knowledge Management Systems (PKMS) is a term that describes how personal information is controlled, the system that organizes and stores data. These systems provide a way for users to control their schedules, contacts, emails, plans/tasks and may assist in data sharing. PKMS organizes the personal data of the individual to incorporate shared data when needed. To understand how PKMS may benefit an organization or personal work flow, an understanding of what knowledge is and what Knowledge Management (KM) is and if there is a benefit to coordinating the systems used. By managing the information within an organization or for personal use, not only will the user find a higher level of accuracy, the information sharing capability should also enhance the productivity and effectiveness of the user.
\end{abstract}

Keywords: Information, Knowledge Management (KM), Personal Knowledge Management (PKMS), Information Sharing

\section{INTRODUCTION}

To understand what Personal Knowledge Management Systems (PKMS) are and how they may possibly benefit a user, an examination of information and knowledge is needed then applied to a system. For a fundamental understanding, consider "a collection of data is not information, a collection of information is not knowledge, a collection of knowledge is not wisdom and a collection of wisdom is not truth" [10]. Understanding there needs to be a connection or relationship with the data, "when a pattern exists between the data and information, the pattern has the potential to represent knowledge" [10]. Without the relation to the data, there would be no information since there is no understanding or connection to produce the knowledge. In this collective process, "the whole represents more than the sum of its parts and has a synergy of its own" [10]. Information, by description, "relates to description, definition or perspective-who, what, when and where [10]. Knowledge, by description, "compromises strategy, practice, method or approach-how [10]. "Not all information is valuable" [11] however decisions should be made to what is considered an asset to the organization. Understanding the needs will initiate the knowledge development and be the basis for future expansion.

\section{Knowledge}

Knowledge, by one definition, "is a fluid mix of framed experiences, values, contextual information, expert insight and intuition that provides an environmental and framework for evaluating and incorporating new experiences and information" [14]. Knowledge may be explicit, something that can be shared, observed, stored or inspected. Tacit knowledge can only exist in the person who stores it in their mind. As defined in the Knowledge Spiral [12], the continuum of dialogue and learning by doing connects explicit knowledge to tacit or internal knowledge. This model shows how interrelated the two types of knowledge are and how they can easily be connected or disconnected. If the spiral is not a continuum between both tacit and explicit, the knowledge may not grow or have the potential to be developed further. 


\section{Issues in Information Systems}

Volume 13, Issue 2, pp. 82-89, 2012

\section{Knowledge Spiral}

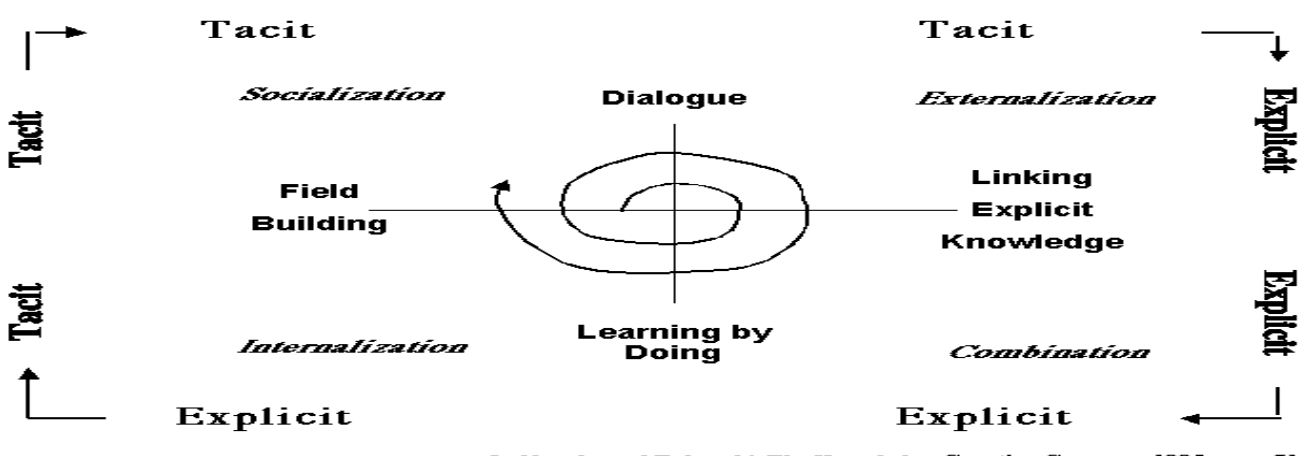

"Knowledge is power. An open culture encourages people to share their views, ideas \& opinions while lack of inhibits sharing knowledge" [9]. IT systems may store the information but the information is useless if it is not used and shared. The "Basic Knowledge Processes" [3] shows the interrelationship between what is in the world relating to what is usable in the organization and what is the outcome from the information. Looking at the information system, we acquire the information; we produce knowledge from the information, share the knowledge then spread the knowledge through the organization. Another system could be acquiring knowledge via training and research, develop the knowledge, strategize and retain knowledge then learn. The cycle may continue or work simultaneously with other information. This concept will enhance the knowledge management practices of the organization or individual.

\section{Basic Knowledge Processes}

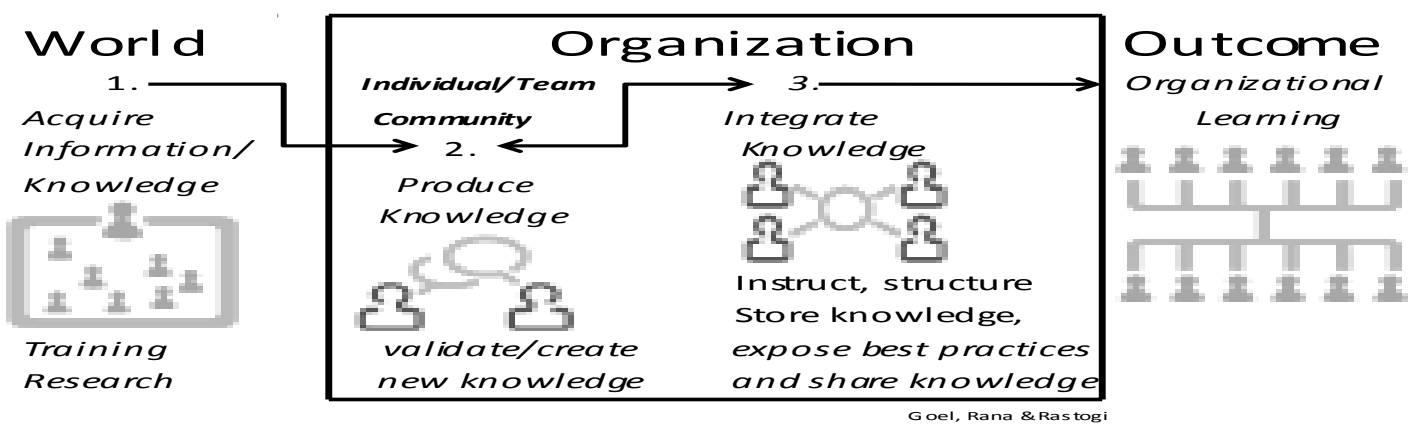

\section{Knowledge Management}

By developing an internal process, knowledge may flow straightforwardly. However, to understand where PKMS may fit, we first should understand Knowledge Management (KM). KM encompasses development, strategies, planning as well as interpersonal controls, relationships and organization. KM addresses relative issues to internal processes. In searching for the holistic definition of KM, most researchers find there is no common meaning. In the broadest sense, "KM is the process though which organizations generate value from their intellectual and knowledge based assets" [11]. Levinson also acknowledged keeping in mind that technology may be a part of the process, it is not KM. This also relates to many parts of an organization and interweaves between explicit and tacit knowledgewhat is known and what is learned. " $\mathrm{KM}$ is a fluid mix of framed experience, values, contextual information, expert 


\section{Issues in Information Systems}

Volume 13, Issue 2, pp. 82-89, 2012

insight, and intuition that provides an environment and framework for evaluating and incorporating new experiences and information" [14]. How successful KM is depends on the processes and many other considerations or needs, not just the software driving it. "KM enables the creation, distribution and exploration of knowledge to create and retain greater value from your core business competencies [14]. In the Knowledge Management Scenario below, the flow between each step from knowledge creation, knowledge capture, knowledge structure and knowledge sharing can procedurally develop a process for understanding KM [13]. The intent is to apply, use and leverage knowledge, in turn, creating more or a higher level of knowledge via interaction.

\section{Knowledge Management Scenario}

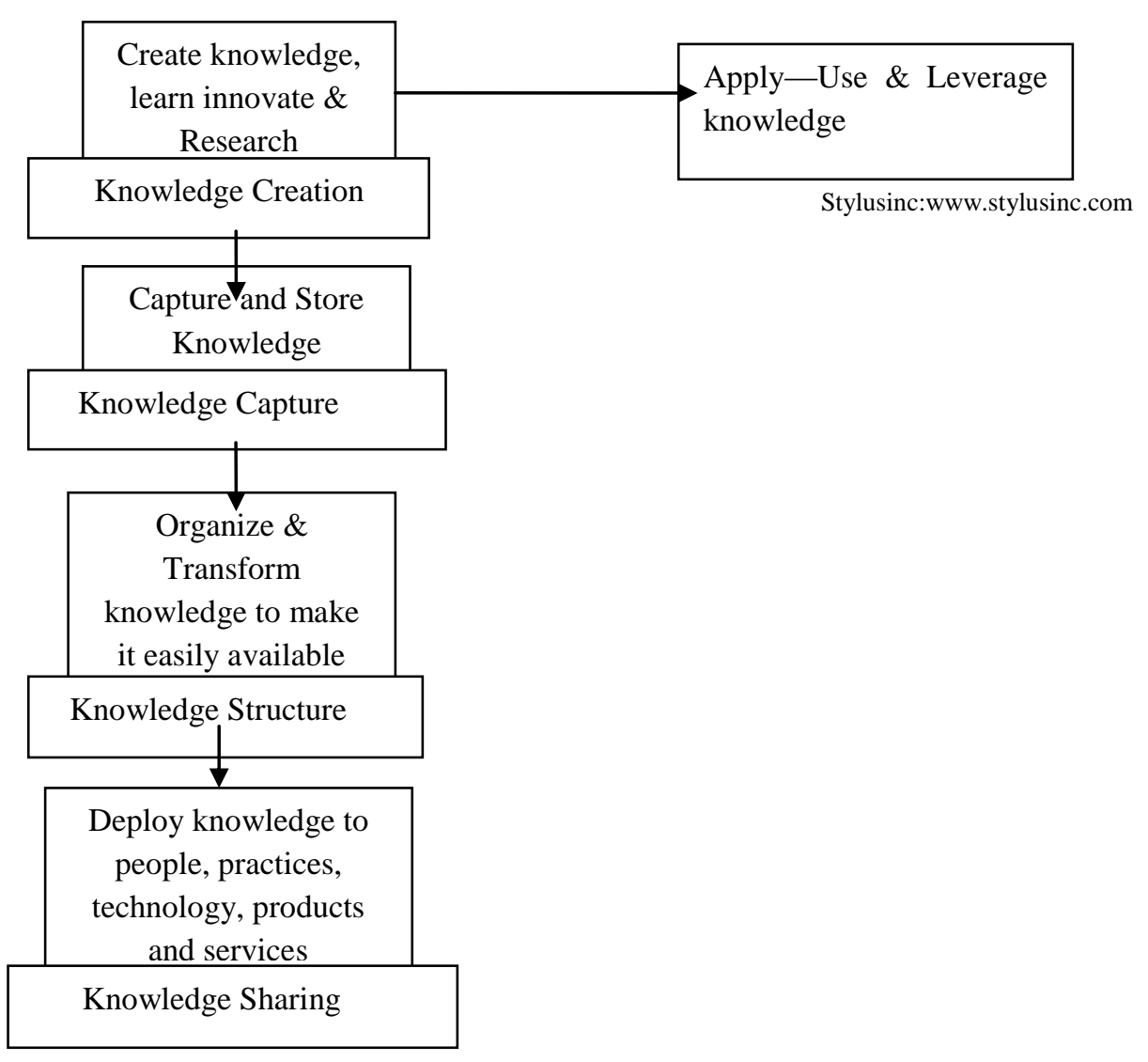

\section{Personal Knowledge Management}

Interaction is equally important in creating knowledge. To not only have access but to have the capability to update, store and organize as needed, is what produces a useable tool. Storing inaccessible information is useless. Information, developed within a basic process, adding in a management scenario, then relating it to a continual process, such as the Personal Knowledge Management by Harold Jarche [7], would allow an understanding of how the information system evolves. The Jarche process consists of four internal actions (sort, categorize, retrieve and make explicit) and the three externally focused ones (connect, contribute, exchange). 


\section{Issues in Information Systems}

Volume 13, Issue 2, pp. 82-89, 2012

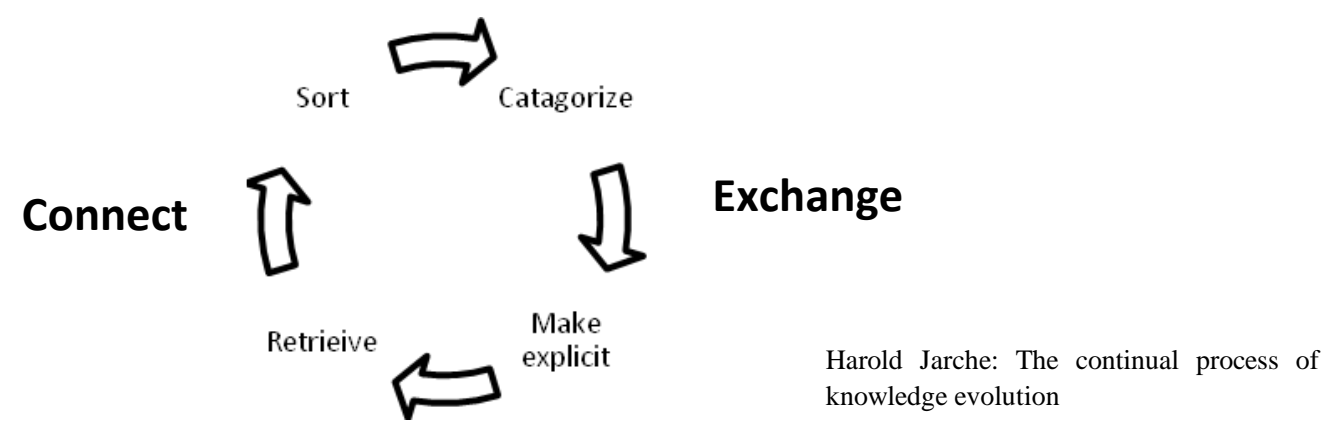

Similar to knowledge, PKMS includes processes relating to acquiring information (connecting), producing, team processes and validating(exchange), and integrate, store and share (contribute). This would be another layer in the process of determining what is needed and how it is acquired, shared and continued. While continuing to build from this infrastructure, consider the significance of KM. "The value of KM relates directly to the effectiveness with which the managed knowledge enables the members of the organization to deal with today's situations and effectively envision and create their future" [13]. Value is internal as well as external and for business, may contribute to ROI or for a not for profit, this may benefit or add to services provided to the public. Another important part of the value of KM is to understand the usefulness and reliability of an organized system. This will not only provide present merit but future value may be invaluable. A reliable process can only enhance the system that will be chosen. $\operatorname{PKM}(\mathrm{S})$ is also one way of addressing the issue of TMI (too much information) [7].

\section{Personal Knowledge Management System (PKMS)}

PKMS is information; it is also a self-managing system, a collection of data, file systems, documents, spread sheets, note taking, including explicit and tacit knowledge. "In PKMS, we often deal with knowledge that is somewhere in the middle of these extremes" [15]. Another way of understanding PKMS would be "the field to Personal Information Management aims to help individuals to manage all artifacts in the personal space of information" [15]. Software companies have developed PKMS, however, before looking at the software options, consider what PKMS means to the average user. Personal information, traits, collection of information related to personal needs, may be shared, text, video, non-atomic data, and both internal and external data are some of what makes up PKMS. Think about what you use every day, what you come in contact with, how you organize it, and prioritize the information. "[PKMS] Its core issues include the accessibility and meaningfulness of information and knowledge, the maintenance of social networks and effective engagement with personal capital" [8].

Along with accessibility and storing information, the primary focus of PKMS is individual usage. The process could be as simple as the individuals adding the information to the system, filling in the blanks, which create the knowledge. "At first glance PKM's stressing the individual over their organization would seem to inherently avoid KM's top-down systematic issues" [8]. Whereas some individual users look at a more technical approach others may use a more social-organizational approach however, "embracing an interdisciplinary approach to PKMS is key" [8]. PKMS offers a connection between the two, creating what is needed based on the process.

PKMS is most effective when the organization realizes the true meaning is individual use. Organizational knowledge management would capture the data for the organization; PKMS would organize the personal data of the individual to incorporate shared data when needed. Accessibility for the individual user is priority and personal. Although the systems may be shared, the purpose is to organize the user. PKMS organizes the personal information so the individual may be more productive and better prepared. "Leading software companies have thus competed in 


\section{Issues in Information Systems}

Volume 13, Issue 2, pp. 82-89, 2012

developing personal knowledge management systems (PKMS) in response to this market request" [2]. What should you consider when looking for a personal management desktop?

\section{Versions of PKMS}

Questions to be considered should include: What will your operating system support? What are your needs? What do you use most often? Do you have information that needs organized? Will it be accessible to other devices? Do you chat/blog/tweet? Are you currently happy with what you are using or would you like to boost your current desktop? Will this be an organizational decision or personal/individual decision? Is Right to Know or Freedom of Information Act a consideration for your organizations PKMS? (For example will personal information such as phone numbers or appointments be on the system?) Also take into consideration "there are enough tools and technologies available to confuse an individual and finding the correct information, organizing it and securing it for future use is still a challenge" [1]. Once you have considered these questions, look for programs that meet your needs. There are several examples of PKMS (Prism ${ }^{\mathrm{TM}}$, Outlook ${ }^{\mathrm{TM}}$, GM Desk ${ }^{\mathrm{TM}}$ or WIKI ${ }^{\mathrm{TM}}$ ); however for the purpose of this paper, we will use Google ${ }^{\mathrm{TM}}$ Desktop. In looking at the homepage, direct links are available for personal information. While examining the page, it is easy to see mail, files, folders and other personal communications such as chats. This desktop operates in real time so there is no delay in updating.
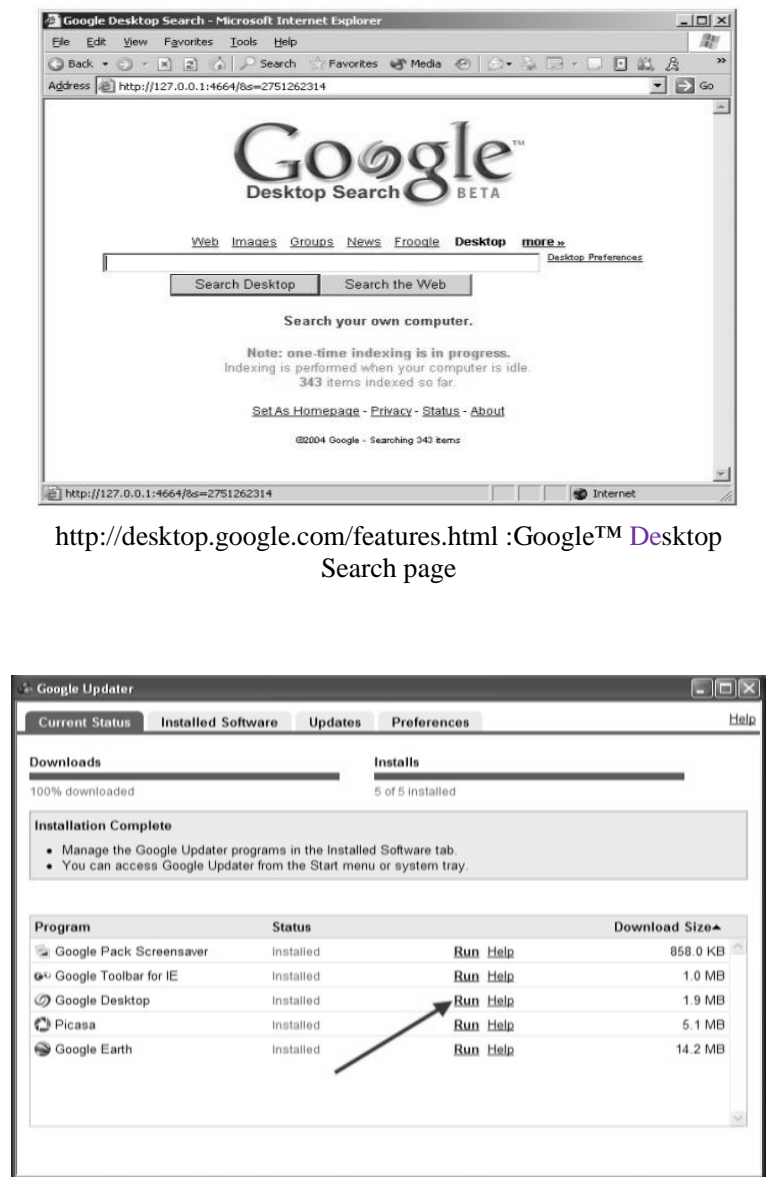

http:/www.terryscomputertips.com/computers/google-desktop-free-software-to-search-your-computer 


\section{Issues in Information Systems}

Volume 13, Issue 2, pp. 82-89, 2012

In looking at Google ${ }^{\mathrm{TM}}$ Desktop, it is noted that there are indexes that permit text files, Microsoft Word ${ }^{\mathrm{TM}}$ documents, Power Point ${ }^{\mathrm{TM}}$, all on the hard drive. Email is accessible through Outlook ${ }^{\mathrm{TM}}$ or Outlook Express $^{\mathrm{TM}}$ and AOL Instant MessengerTM. Photographs, MP3 and movies are indexed by filenames. Searching is easy and is based on a query, just like a Google ${ }^{\mathrm{TM}}$ search, except you are searching your personal information. Additionally, you may sort by relevance as well. Downloading is simple and takes minimal time. Also, take into consideration how often access would be needed. As a daily calendar, the display shows events, schedules, appointments and options to change or add into the real time calendar. Adding options is a click into the desktop. Easy access is important as well as quick visuals that show the events may be important to the user. If you are looking from an organizational standpoint, consider what your staff is using currently. Does the desktop permit ease of organization? Will staff understand, use, and accept the change? Will staff share information?

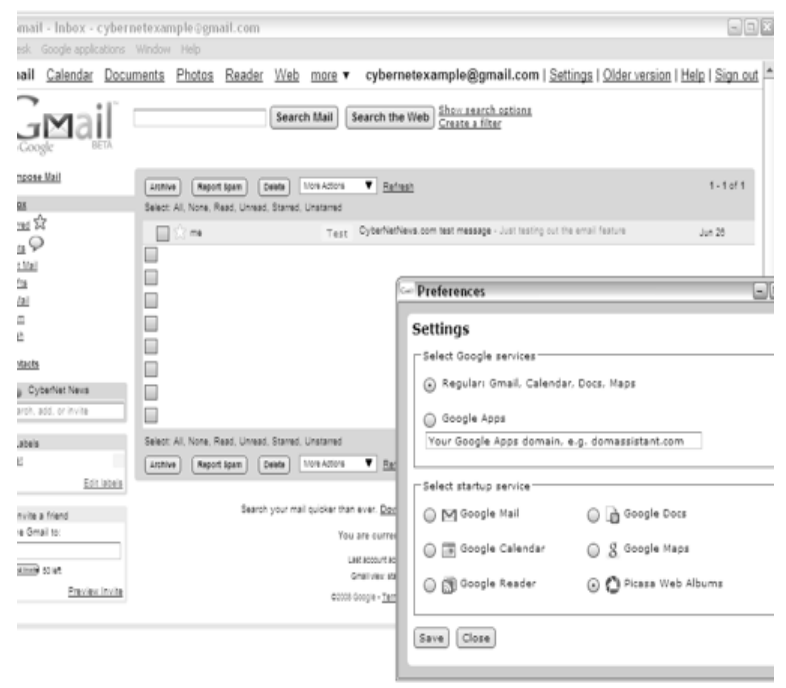

http://cybernetnews.com/unofficial-google-desktop-suite
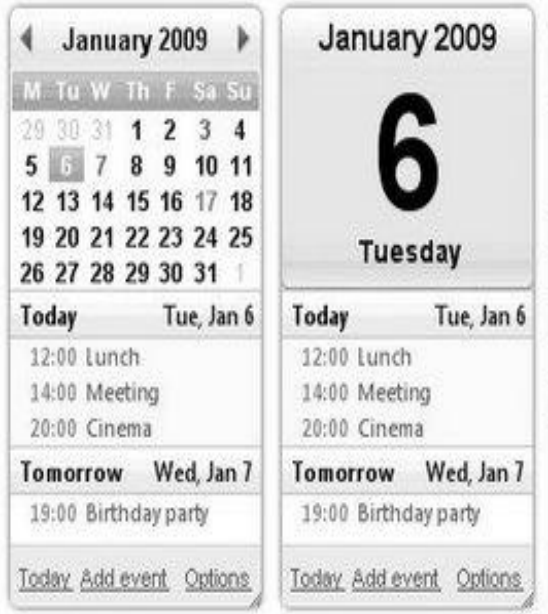

\begin{tabular}{|l|}
\hline Av Agenda \\
\hline Today Tue, Jan 6 \\
\hline 12:00 lunch \\
14:00 Meeting \\
20:00 Cinema \\
\hline Tomorrow Wed, Jan 7 \\
\hline 19:00 Birthday party \\
\hline Thu, January 8 \\
\hline no events \\
\hline Fri, January 9 \\
\hline no events \\
\hline Todox Addevent Oagtions \\
\hline
\end{tabular}

http://gmailblog.blogspot.com/2009/01/get-calendar-on-your-google-example of calendar page 


\section{Issues in Information Systems}

Volume 13, Issue 2, pp. 82-89, 2012

Google ${ }^{\mathrm{TM}}$ Desktop's platform "is free and online users can gain access to it, it provides a wide variety with high system reliability and it offers powerful taxonomy processes and desktop search tools that supports users" [2]. In the research study conducted by Doong and Wang, "Findings have revealed that online users' differences in involvement and innovativeness were associated with significant differences in their PKMS user behaviors" [2]. The research continues to verify "user's involvement was the primary predictor of PKMS user frequency, while user innovativeness was found to be the main predictor of the number of PKMS functions used" [2].

\section{CONCLUSION}

To understand what PKMS is needed, consider what you use currently and what you could use to enhance your productivity. Looking at data and knowledge would be the first step. How is tacit and explicit knowledge shared, stored and used. Develop an internal process that describes what is being taken in, how it is being taken in, shared used and recreated and made into useable knowledge. Consider what is needed, what is missing and how could the process be better developed and used. The goal is to create an accessible and user friendly process for the management of information. This management system supports the concepts of sharing, creating and storing information until it is needed, added to and deleted. Also, consider what system you are using currently and may this be enhanced or does a new system need to be considered. Once the need is determined, the choice should be easier.

When the PKMS is decided, keep in mind that one purpose will be to retrieve the information. "To compete and succeed in today's information-oriented environment, knowledge workers need to exercise information literacy skills that focus on critical thinking, problem solving, creativeness, decision making and secured sharing" [1]. The purpose of the PKMS is for storing, categorizing, organizing and retrieving thus contributing to personal knowledge. To control the knowledge is to understand where and how it may be stored for retrieval.

Another value of PKMS is sharing knowledge. Information sharing often creates an understanding of each person's part in the entire picture. The give and take of information frequently produces a form of brainstorming that regularly gives information new life. The access to teams, groups and other resources may often be invaluable. There are also simple and basic advantages of a PKMS such as allowing access to calendars permitting meetings to be scheduled easier, without all of the back and forth emails, reducing not only time but the volume of emails coming in.

Finally, the value of knowledge may only be determined if the information is accessible. If you cannot find the information, how valuable is it? For example, keeping temporary emails is fine in an Outlook ${ }^{\mathrm{TM}}$ folder, but once that information becomes part of the project, is it moved to a permanent folder or is it mixed with other information? The progression of data accessibility permits the development of a pattern that forms a relationship. With this connection, data become information that permits knowledge to be shared.

PKMS users will value the ease in creating, sharing and organizing their information. Understanding knowledge, knowledge management, management systems will help in choosing the correct PKMS. By optimizing the use, the system will permit a higher level of accuracy and sharing of information. Duplication of information or complete rewrites will not be necessary due to the information being live. This in turn will enhance productivity, saving time, using less server space and may make life just a little easier.

\section{REFERENCES}

1. Agnihotri, R. \& Troutt, M. (2009). The effective use of technology in personal knowledge management. Online Information Review. Vol.33, No 2,2009, pp 329-342.

2. Doong, H. \& Wang, H. (2009). Predictors of diverse usage behavior towards personal knowledge management systems. Online Information Review. Vol 33, No 2, 2009, pp 316-328.

3. Goel, Rana \& Rastogi (2010). Knowledge Management as a process to develop sustainable Competitive Advantage. $\quad$ South Asian Journal of Management. Jul-Sep 2010, 17, 3;ABI/INFORM Global, p 104116.

4. http://cybernetnews.com/unofficial-google-desktop-suite/ 


\section{Issues in Information Systems}

Volume 13, Issue 2, pp. 82-89, 2012

5. http://desktop.google.com/features.html

6. http://gmailblog.blogspot.com/2009/01/get-calendar-on-your-google-desktop.html

7. Jarche, H. Creating your PKM Process. http://www.jarche.com/2009/07/creating-your-pkm-processes/

8. Jones, R. (2009). Personal knowledge management through communicating. Online Information Review. Vol. 33, Nov 2, 2009, pp 225-236. DOI:10.1108/14684520910951186

9. Karishma, A. Knowledge Management Issues (2009). http://www.karishmadaswani/index.php/2009/10/knowledge-mamagement.

10. Knowledge Management-Emerging perspectives. Retrieved from: www.systemsthinking.org

11. Levinson, M. (2007). Knowledge Management Definition and Solutions. CIO. Retrieved form http://www.cio.com/article/40343/knowledge_managment_definitions_and_solutions

12. Nonaka \& Takeuchi (1995). The Knowledge Creating Company. P 7.

13. Stylusinc Web Development Scenario-knowledge management. Stylusinc: www.stylusinc.com. Retrieved form http://styluinc.com/common/scenarios $/ \mathrm{km} / \mathrm{php}$

14. Tiwana, A. (2002). The Knowledge Management Toolkit. Upper Saddle River, NJ: Pearson Education, Inc.

15. Volker, M. \& Haller, H. (2008). Conceptual data structures for personal knowledge management. Online Information Review. Vol. 33, No 2, 2009, pp. 298-31. DOI 10.1108/14684520910951221 